\title{
Nörofibromatozis Tip-1 Tanısıyla Takipli Çocuk Hastalarda Kardiak Aritmi Belirteçlerinin Değerlendirilmesi: Tek Merkez Çalışması
}

\author{
Evaluation of Cardiac Arrhythmia Markers in Pediatric \\ Patients with a Diagnosis of Neurofibromatosis Type-1: A \\ Single Center Study
}

${ }^{1}$ Hatay Mustafa Kemal Üniversitesi, Tıp Fakültesi, Çocuk Nörolojisi, Hatay, Türkiye ${ }^{2}$ Hatay Mustafa Kemal Üniversitesi, Tıp Fakültesi, Çocuk Kardiolojisi, Hatay, Türkiye

Yazışma Adresi: Yılmaz Akbaş, Hatay Mustafa Kemal Üniversitesi, Tıp Fakültesi, Çocuk Nörolojisi, Hatay, Türkiye e-mail: mberf@hotmail.com

Geliş Tarihi/Received: 18 Kasım 2020 Kabul Tarihi/Accepted: 1 Şubat 2021

\author{
Yılmaz Akbaş ${ }^{1}$, Nuh Yılmaz ${ }^{2}$
}

\begin{abstract}
Öz
Amaç: Bu çalışmamızda ki amacımız Nörofibromatozis tip 1 tanılı hastalarda kardiak tutulumun sıklığı ve çeşitliliğini gösterip diğer klinik bulgularla karşılaştırılmasıdır.

Hastalar ve Yöntem: Çocuk Nöroloji Polikliniği'ne 01/09/2019-01/09/2020 tarihleri arasında Nörofibromatozis tip 1 tanısı alan hastalar çalışmaya dahil edildi. Hastaların dosya kayıtlarından demografik bilgileri, muayene bulguları, beyin manyetik rezonans görüntüleri toplandı. Elektrokardiografi ve ekokardiografi Çocuk Kardioloji Uzmanı tarafından incelenip kayıt altına alındı.

Bulgular: Calışmaya 17 hasta kabul ettik. Altı hastamız $(\% 35,3)$ sporadik 11 hastamız $(\% 64,7)$ familyal Nörofibromatozis-1'di. Hastalarımızın tamamında ciltte cafe au late lekeleri $(\% 100), 10$ tanesinde $(\% 58,8)$ aksiller ve/veya inguinal çillenme $3(6 / 17-\% 35,2)$ tanesinde optik glioma ve papil ödemi 3 tanesinde ise lisch nodülü tespit ettik. Kardiyak açıdan yaptığımız incelemede 1 hastada QT uzunluğu, 3 hastada subendokardiyal nörofibromla uyumlu nodüler görünüm, 3 hastada mitral yetmezlik, 1 hastada patent foramen ovale, 1 hastada atrial septal defekt, 1 hastada ise biküspit aorta vardı.

Sonuç: Çalışmamızda 3 hastamızda subendokardiyal nodüler hiperekojen görüntü mevcuttu. Bu bulgular oldukça nadir olmasına rağmen bizim 17 hastamızın 3'ünde saptanması bu patolojinin daha sık olabileceğini düşündürmektedir.
\end{abstract}

\begin{abstract}
Anahtar Kelimeler: Nörofibromatozis 1, elektrokardiografi, ekokardiografi, çocuk, nörofibrom Abstract

Aim: Our aim is to show the fequency and variety of cardiac involvement of Neurofibromatosis type 1 patients and to compare them with other clinical findings.

Patients and Methods: Patients diagnosed with Neurofibromatosis type 1 in Pediatric Neurology Clinic between 01/09/2019 and 01/09/2020 were Demographic information, examination findings, brain magnetic resonance images were collected from the files of the patients. Electrocardiography and echocardiography were examined and recorded by the Pediatric Cardiology Specialist.

Results: We accepted 17 patients. Six patients (35.3\%) were diagnosed with sporadic Neurofibromatosis type 1 , while 11 patients $(64.7 \%)$ had familial Neurofibromatosis type 1 . All of our patients had cafe au late spots on the skin. In addition, $10(58.8 \%)$ patients also had axillary and / or inguinal freckles. We detected optic glioma in 3 of our patients with ocular involvement, and lish nodules in 3 of them with papillary edema. In cardiac examination, we found QT length in 1 patient's and we detected nodular appearance compatible with subendocardial neurofibroma in 3 patients

Conclusions: In our study, unlike the literature, subendocardial nodular hyperechogenic appearance was present in 3 patients. Although these findings are quite rare, subendocardial nodular hyperechogenic images in 3 of our 17 patients suggest that this pathology may be more common
\end{abstract}

Key words: Nörofibromatozis tip 1, elektrokardiografi, ekokardiografi, children, neurofibroma

Atıf yapmak için: Akbaş Y, Yılmaz N. Nörofibromatozis Tip-1 Tanısıyla Takipli Çocuk Hastalarda Kardiak Aritmi Belirteçlerinin Değerlendirilmesi: Prospektif Tek Merkez Çalısması. Selcuk Med J 2021;37(2): 113-117
Açıklama: Yazarların hiçbiri, bu makalede bahsedilen herhangi bir ürün aygıt veya ilaç ile ilgili maddi çıkar ilişsisine sahip değildir. Araştırma, herhangi bir dış organizasyon tarafından desteklenmedi. Yazarlar çalışmanın birincil verilerine tam erişim izni vermek ve derginin talep ettiği takdirde verileri incelemesine izin vermeyi kabul etmektedirler. 


\section{Gíriş}

Nörofibromatozis tip 1(NF-1) santral sinir sisteminin en sık görülen otozomal dominant geçişli sendromlarından biridir. Tahmini insidansı 1/2500 doğum ve tahmini prevalansı ise 1/2000-4000'dir (13). Tüm ırklarda ve cinsiyetlerde eşit sıklıkta izlenir (4). Hastalığın oluşmasında ki neden RAS/mitogenactiveted protein kinase (MAPK) sinyal yolağının bozulmasıdır(5). NF-1 geni 17. kromozomda yerleşmiş olup neurofibromin adında bir proteini kodlamaktadır. $\mathrm{Bu}$ gende meydana gelen mutasyon neurofibromin üretimini engelleyip RAS/mitogen-activeted protein kinase (MAPK) sinyal yolağının bozar. Sonuç olarak bening ya da malign tümör gelişimine neden olur (6). Öncelikle cilt ve beyinde görülen bu oluşumlar birçok doku ve organda da meydana gelebilir. Neurofibromin RAS aktivitesini azaltarak gelişmekte olan kalpte, epitelyal ve mezenkimal proliferasyonu düzenler. Neurofibromin üretimi olmayan farelerde endokardiyal hiperproliferasyon gösterilmiştir (7). NF-1 hastalarında da çeşitli kardiyak tutulumlar görülür. Literatüre bakıldığı zaman NF-1 için yapılan çalışmaların çoğunu cilt tutulumları santral sinir sistemi tutulumları ve nörogörüntüleme özellikleri üzerine yapıldığı anlaşılıyor. Kardiyak tutulum ile ilgili çalışmalar bunlara nazaran daha az sayıda olup daha eski tarihli çalışmalardır.

$\mathrm{Bu}$ çalışmamızda ki amacımız bölgemizde takip ettiğimiz NF-1 hastaların kardiyak tutulumlarının değerlendirilmesi ve diğer klinik bulgularla karşılaştırılmasıdır. Bu çalışma ile kardiyak tutulumun sıklığını ve çeşitliliğini göstermek istedik

\section{HASTALAR VE YÖNTEM}

Hatay Mustafa Kemal Üniversitesi Klinik Çalışmalar Etik Kurulu'ndan 22/10/2020 tarihli 15 no' lu kararla etik kurul izni alındı. Çocuk Nöroloji Polikliniği'ne 01/09/2019-01/09/2020 tarihleri arasında NF-1 şüphesiyle başvuran hastalar Çocuk Nöroloji Uzmanı tarafından değerlendirildi. Daha sonra National
Institutes of Health NF-1 tanı kriterlerine (Tablo 1) göre NF-1 tanısı alan hastalar çalışmaya dahil edildi. Çalışmaya dahil edilen hastalar Çocuk Kardiyoloji Uzmanı tarafından muayene edilip ekokardiografi (EKO) ve elektrokardiografi (EKG) çekimleri yapılıp değerlendirildi.

Tüm hastalara 2D, Doppler ve M-Mode görüntüleme teknikleri kullanılarak tam bir transtorasik ekokardiyografik inceleme yapıldı. Ekokardiyografi işleminde Philips IE-33 (2014, Canada) ekokardiyografi cihazı ve değişken frekanslı (büyük çocuklarda $\mathrm{S5-2} \mathrm{mHz}$ ve küçük çocuklarda S8-3 mHz) faz array transduserler kullanıldı. Ekokardiyografi protokolü Amerikan Society of Echocardiography kılavuzuna uygun olarak yapıldı. Buna göre subkostal, apikal 4 boşluk, parasternal kısa eksen, parasternal uzun eksen, suprasternal uzun eksenlerden ekokardiyografi görüntüleri alınarak cihazın hafızasına kaydedildi. Parasternal uzun eksen görüntülerinden interventriküler septum ve sol ventrikül serbest duvarına mümkün olduğunca dik açıda ve mitral kapakların birleşim bölgesinin hemen önünden geçirilen eksen boyunca M-Mode görüntüleri alındı. M-Mode incelemesinde septum ve sol ventrikül arka duvarının sistolik ve diastolik kalınlıkları, sol ventrikülün sistolik ve diyastolik çapları, bunlardan hesaplanan sol ventriküler ejeksiyon fraksiyonu (LVEF), sol ventriküler fraksiyonel kısalma (LVFS) değerleri ölçülerek kaydedildi. İşlemler sırasında hastaların sakin olmasına özen gösterildi. Mitral, aortik, triküspit ve pulmoner kapak patolojileri renkli Doppler ve CW Doppler kullanılarak araştırıldı. Kapak yetersizlikleri azdan çoğa doğru eser, minimal, hafif, birinci, ikinci, üçüncü derece ve ağır olarak sınıflandırıldı.

Çalışmaya alınan tüm hastalara 12 derivasyonlu standart EKG çekildi. EKG çekimleri Amerika Kardiyoloji Derneğinin kriterlerine uygun olarak yapıldı (8). Hastaların dosya kayıtlarından demografik bilgileri, muayene bulguları, beyin manyetik rezonans

Tablo 1. Nörofibromatozis tanı kriterleri
1. Puberte öncesi $5 \mathrm{~mm}$, püberte sonrası $15 \mathrm{~mm}$ 'den büyük 6 veya daha fazla cafe au late lekesi
2. Koltuk altı veya kasık bölgesinde çillenme
3. İki nörofibrom veya bir pleksiform nörofibrom
4. Optik yolak gliomu
5. Kemik lezyonu
6. En az iki iris hamartomu (Lisch nodülü)
7. NF-1 tanısı konulmuş birinci derece akraba

* Bu kriterlerden en az ikisi olmalıdır. 
görüntüleri (MRG) toplandı. Hastaların EKG ve EKO tetkikleri Çocuk Kardiyoloji Uzmanı tarafından incelenip kayıt altına alındı. Hipertansiyonu olanlar, böbrek patolojisi olanlar, akut eklem romatizması veya enfektif endokardit gibi sekonder kardiyak patolojisi olanlar ve ek bir genetik bozukluğu mevcut olan hastalar çalışma dışı bırakıldı. İstatistik analizi için IBM SPSS 21 fora Windows programı kullanılmıştır. Verilerin dağılımı Kolmogorov Smirnov testi kullanıldı. Kategorik verilerin değerlendirilmesi için Ki kare testi kullanıldı. Tüm analizlerde $p<0,05$ istatistiksel olarak anlamlı kabul edildi.

\section{BULGULAR}

Merkezimizden çalışmaya 17 hasta kabul ettik. Median yaşı 7 yıl (min:1-max:15) olan hastaların 10/17'si $(\% 58,8)$ kızdı. Hastalarımız demografik ve klinik özellikleri tablo 2'de özetlenmiştir. Altı hastamız sporadik NF-1 tanısı alırken 11 hastamızda familyal NF-1 mevcuttu. Hastalarımızın tamamında ciltte cafe au late lekeleri görüldü buna ek olarak $10(\% 58,8)$ hastamızda aksiller ve/veya inguinal çillenme de vardı. Göz tutulumu olan hastalarımızın (6/17-\%35,2) 3 tanesinde optik glioma ve papil ödemi 3 tanesinde ise lisch nodülü tespit ettik. Santral sinir sistemi (SSS) tutulumuna baktığımızda $8(\% 47)$ hastamızın beyin MRG'lerinde çeşitli tutulumlarla karşılaştık. Kardiyak açıdan yaptığımız incelemede ileti bozuklukları için çekilen EKG'lerin değerlendirilmesinde sadece bir hastada QT uzunluğu saptadık. Yine kardiyak yapısal patolojiler için yaptığımız EKO 'da 9/17 (\%52,9) hastada çeşitli bulgular gördük. Özellikle hastaların 3 tanesinde subendokardiyal nörofibromla uyumlu görüntü( Şekil 1) vardı. Hastalarımızın MRG, EKO ve EKG verileri tablo 3'te gösterilmiştir.

\section{TARTIŞMA}

Literatüre bakıldığı zaman NF-1 ile ilgili olan

Tablo 2. Hastaların demografik ve klinik özellikleri

\begin{tabular}{lll}
\hline $\begin{array}{l}\text { Yaş } \\
\text { Cinsiyet }\end{array}$ & $7,4 \pm 4,6($ meantSD) \\
& $\begin{array}{l}\text { Erkek } \\
\text { Kadın }\end{array}$ & $7 / 17(\% 41,2)$ \\
Uyruk & & $10 / 17(\% 58,8)$ \\
& Türk & $12 / 17(\% 70,6)$ \\
Aile öyküsü & Suriyeli & $5 / 17(\% 29,4)$ \\
Göz tutulumu & & $11 / 17(\% 64,7)$ \\
Cilt tutulumu & & $6 / 17(\% 35,2)$ \\
SSS tutulumu & & $17 / 17(\% 100)$ \\
*SD: Standart deviasyon, SSS: Santral sinir sistemi
\end{tabular}
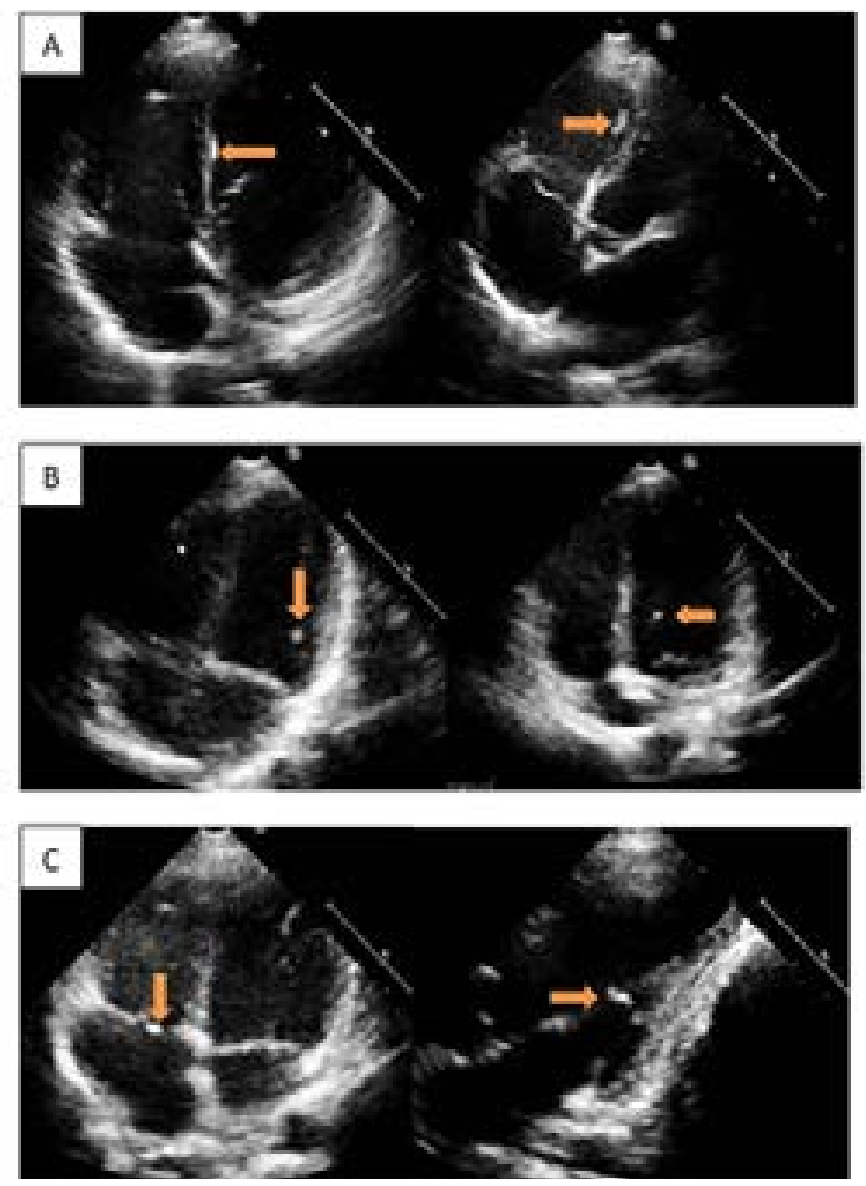

Şekil 1. Interventriküler septumun sağ ve sol ventrikül subendokardial bölgesinde hiperekojen görünüm $(A)$, sol ventrikül içerisinde serbest duvar ve septuma yakın ekojenik odaklar (B), triküspit kapağın atrial yüzeyinde ve mitral kapak komşuluğunda hiperekojen görünüm(C).

çalışmaların SSS, cilt, göz tutulumları ve bunların tedavisi üzerine yoğunlaştığını görüyoruz. Kardiyak tutulum üzerine yapılan çalışmalar son yıllarda artmış fakat bu çalışmalarında büyük çoğunluğunu vaka sunumları oluşturmuştur. Yapılan bu çalışmalar incelendiği zaman NF-1 hastalarında kardiyak tutulum açısından kapak yetmezlikleri, kardiomyopatiler, atrial ve ventriküler septal defekler ve aort koarktasyonlarının daha sık görüldüğü bildirilmiş (912). Fakat son yıllarda vaka sunumu çalışmalarda bu hastalarda miokardial veya perikardial tümoral oluşumlar bildirilmeye başlandı $(13,14)$.

Biz çalışmamızda 3 hastada mitral yetmezlik, 1 mitral valv prolapsusu, 1 biküspit aorta, 1 atrial septal defekt ve 1 patent foramen ovale tespit ettik. Çalışmamızın ilginç tarafı ise 3 hastada 
Tablo 3. Hastaların beyin ve kardiak görüntüleme bulguları

\begin{tabular}{|c|c|c|c|c|c|c|}
\hline Hasta & MRG & EKO & PR & QRS & QT & QTC \\
\hline 1 & $\mathrm{~N}$ & & 125 & 76 & 343 & 372 \\
\hline 2 & $\begin{array}{l}\text { Globus pallidus, } \\
\text { Talamus }\end{array}$ & $\mathrm{N}$ & 84 & 142 & 337 & 375 \\
\hline 3 & $\mathrm{~N}$ & $\begin{array}{l}\text { İnterventriküler septumda, triküspit } \\
\text { kapak üzerinde mitral kapak } \\
\text { komşuluğunda hiperekojenite }\end{array}$ & 134 & 82 & 275 & 370 \\
\hline 4 & $\mathrm{~N}$ & Biküspit aorta & 118 & 86 & 384 & 440 \\
\hline \multirow[t]{2}{*}{5} & Serebellum & & & & & \\
\hline & Bazal ganglionlar & $\mathrm{N}$ & 105 & 106 & 336 & 443 \\
\hline 6 & $\mathrm{~N}$ & Mitral vavl prolapsusu, mitral yetmezlik & 110 & 104 & 319 & 391 \\
\hline 7 & $\mathrm{~N}$ & $\mathrm{~N}$ & 80 & 120 & 320 & 381 \\
\hline \multirow[t]{2}{*}{8} & Optik gliom & & & & & \\
\hline & Globus pallidus & $\mathrm{N}$ & 100 & 120 & 300 & 470 \\
\hline 9 & Optik gliom & $\mathrm{N}$ & 80 & 120 & 240 & 392 \\
\hline 10 & $\mathrm{~N}$ & Mitral yetmezlik & 80 & 120 & 320 & 348 \\
\hline 11 & İnternal kapsül & Mitral yetmezlik & 60 & 120 & 240 & 379 \\
\hline 12 & Globus pallidus & Patent foramen ovale & 120 & 132 & 341 & 389 \\
\hline \multirow[t]{2}{*}{13} & $\mathrm{~N}$ & Sol ventrikül içinde septum & & & & \\
\hline & & Komşuluğunda hiperekojenite & 100 & 92 & 350 & 415 \\
\hline \multirow{3}{*}{$\begin{array}{l}14 \\
15\end{array}$} & $\mathrm{~N}$ & Atrial septal defekt & 100 & 160 & 280 & 449 \\
\hline & Globus pallidus, & & & & & \\
\hline & Serebellum & $\begin{array}{l}\text { Sol ventrikülde subendokardial } \\
\text { hiperekojenite }\end{array}$ & 80 & 140 & 340 & 432 \\
\hline 16 & Serebral beyaz cevher & $\mathrm{N}$ & 94 & 140 & 360 & 436 \\
\hline 17 & Optik gliom & $\mathrm{N}$ & 110 & 116 & 377 & 407 \\
\hline
\end{tabular}

*EKO: Ekokardiografi, MRG: Manyetik rezonans görüntüleme, N: Normal

subendokardiyal nodüler hiperekojen görüntü mevcuttu. Bu bulgular oldukça nadir olmasına rağmen bizim 17 hastamızın 3 tanesinde subendokardiyal nodüler hiperekojen görüntü saptanması bu patolojinin daha sık olabileceğini düşündürmektedir. Ayrıca daha önce yapılan çalışmalarda NF-1 hastalarında kardiyak bulguların görülme sıklığı \%16,9-\%27 arasında değişmektedir (15). Bizim çalışmamızda ise hastalarımızın \% 52,9'unda en az bir adet kardiyak bulgu mevcuttu. Bu fark ise hem gelişen teknoloji ile görüntüleme cihazlarının daha yüksek kalite ve çözünürlükte görüntü sağlaması hem de bu konuda farkındalığın artmasına bağlı olabilir.

Hastalarımızın EKG'lerini incelediğimizde bir hastamızda QT uzaması tespit ettik. NF-1 hastalarında kardiyak ileti sistemi ile ilgili sınırı sayıda çalışma mevcut. Literatürde vaka düzeyinde çalışmalarda 1 hastada dal bloğu, birkaç hastada ise ani ölüm tespit edilmiş. Ani ölüm gelişen vakalarda vagal sinir komşuluğunda ya da AV noda lokalize nörofibromlara rastlanıımıştır (16-20). Hastalarımızın 3 tanesinde saptadığımız intrakardiyak nodüler yapılar bu hastalarda da aritmi için risk oluşturabilir. Uzun QT'si olan bir NF-1 hastasını yapılmış çalışmalarda saptayamadık. Bu durum ileti sistemine etki eden bir nörofibroma bağlı olabileceği gibi koinsidental olarak saptanmış olabilir. Bu hasta için ileri araştırma yöntemlerini kullanmayı planladık.

Çalışmamız tek merkezde yapılan bir çalışma olduğu için hasta sayısı düşüktü. Bu çalışmamızın zayıf yönü olsa da çalışmamızda NF-1 hastalarında kardiyak tutulumun literatürde bahsedilen oranlardan daha yüksek olması ve oldukça nadir görülen subendokardial oluşumları, bizim 3 hastamızda tespit etmiş olmamız bu çalışmayı değerli kılmaktadır. Ayrıca yine 1 hastamızda kardiyak ileti bozukluğu var. Bu bildiğimiz kadarıyla bu hasta NF-1 uzun QT sendromunun birlikte görüldüğü ilk vakadır. Vagal sinir veya AV nod komşuluğunda ki nörofibromu olan hastalarda ani ölümlerin bildirilmesi, hastalarımızın 3/17 (\%17.6) tanesinde nörofibromla uyumlu görünüm saptanması oldukça dikkat çekicidir. Bu nedenle NF-1 tanılı hastaların kardiyak değerlendirilmelerinin daha dikkatli ve düzenli yapılması gerekmektedir. İlerleyen zamanlarda NF-1 hastalarına kardiyak MRG ile yapılacak çalışmalarla belki bu yapıların gerçek sıklığı tespit edilebilir.

Çıkar Çatışması: Çalışmada herhangi bir çıkar çatışması yoktur. 
Finansal Çıkar Çatışması: Çalışmada herhangi bir finansal çıkar çatışması yoktur.

Yazışma Adresi: Yılmaz Akbaş, Hatay Mustafa Kemal Üniversitesi, Tıp Fakültesi, Çocuk Nörolojisi Posta Kodu:31100 Serinyol/Hatay, Türkiye

Telefon: 05395659592

e-mail: mberf@hotmail.com

\section{KAYNAKLAR}

1. Evans DG, Howard E, Giblin C, et al. Birth incidence and prevalence of tumorprone syndromes: Estimates from a UK family genetic register service. Am J Med Genet A 2010;152A(2):327-32.

2. Kallionpaa RA, Uusitalo E, Leppavirta J, et al. Prevalence of neurofibromatosis type 1 in the Finnish population. Genet Med 2018;20(9):1082-6.

3. Uusitalo E, Leppavirta J, Koffert A, et al. Incidence and mortality of neurofibromatosis: A total population study in Finland. J Invest Dermatol 2015;135(3):904-6.

4. Friedman JM. Epidemiology of neurofibromatosis type 1. Am J Med Genet 1999;89(1):1-6.

5. Rauen KA, Huson SM, Burkitt-Wright E, et al. Recent developments in neurofibromatoses and RASopathies: Management, diagnosis and current and future therapeutic avenues. Am J Med Genet A 2015;167A(1):1-10.

6. Garicochea B, Giorgi R, Odone VF, et al. Mutational analysis of N-RAS and GAP-related domain of the neurofibromatosis type 1 gene in chronic myelogenous leukemia. Leuk Res 1998;22:1003-7.

7. Norton KK, Xu J, Gutmann DH. Expression of the neurofibromatosis I gene product, neurofibromin, in blood vessel endothelial cells and smooth muscle. Neurobiol Dis 1995;2:13-21.8. Kligfield, Pauletal. "Recommendations for the standardization and interpretation of the electrocardiogram: part I: The electrocardiogram and its technology: a scientific statement from the American Heart Association Electrocardiography and Arrhythmias Committee, Council on Clinical Cardiology; the American College of Cardiology Foundation; and the Heart Rhythm Society: Endorsed by the International Society for Computerized Electrocardiology." Circulation vol 115,10(2007):1306-24.

9. Kurien A, John PR, Milford DV. Hypertension secondary to progressive vascular neurofibromatosis. Arch Dis Child 1997;76:454-5.

10. Tedesco MA, Di Salvo G, Natale F, et al. The heart in neurofibromatosis type 1: An echocardiographic study. Am Heart J 2002;143:883-8. CrossRef

11. Lin AE, Birch PH, Korf BR, et al. Cardiovascular malformations and other cardiovascular abnormalities in neurofibromatosis 1. Am J Med Genet 2000;95:108-17.

12. Lama G, Graziano L, Calabrese E, et al. Blood pressure and cardiovascular involvement in children with neurofibromatosis type1. Pediatr Nephrol 2004;19:413-8.

13. Kizawa $M$, Nakagama $Y$, Shindo $T$, et al. Identification of a novel titin variant underlying myocardial involvement in neurofibromatosis type 1. Can J Cardio 2018;34(10):1369. e5-7.

14. Moghadam EA, Navabi Shirazi MA, Mirzaaghayan MR, et al. Intrapericardial neurofibromatosis with coronary involvement: A case report. Arch Pediatr 2018;25(1):39-41.
15. İncecik $F$, Hergüner ÖM, Alınç Erdem $S$, et al. Neurofibromatosis type 1 and cardiac manifestations Turk Kardiyol Dern Ars 2015;43(8):714-6.

16. Rubio Sanz R, Molinero Somolinos F, Herrerro Cristobal A, et al. Bundle branch block in von Recklinghausen disease. Med Clin (Barc) 1981;77:258-9.

17. Chow LT, Shum BS, Chow WH. Intrathoracic vagus nerve neurofibroma and sudden death in a patient with neurofibromatosis. Thorax 1993;48:298-9.

18. Newman A, So K. Bilateral neurofibroma ofthe intrathoracic vagus associated with von Recklinghausen's disease. Am J Roentgenol Radium Ther Nucl Med 1971;112:389-92.

19. Unger PD, Taff ML, Song S, et al. Sudden death in a patient with von Recklinghausen's neurofibromatosis. Am J Forensic Med Pathol 1984;5(2):175-9.

20. Jaffe R. Neuroma in the region of the AV node. Hum Pathol 1981;12:375-6. 